\title{
The common stress responsive
} transcription factor ATF3 binds genomic sites enriched with p300 and H3K27ac for transcriptional regulation

\author{
Jonathan Zhao ${ }^{1 \dagger}$, Xingyao $\mathrm{Li}^{2 \dagger}$, Mingxiong Guo ${ }^{4}$, Jindan $\mathrm{Yu}^{1 *}$ and Chunhong Yan ${ }^{2,3,4^{*}}$
}

\begin{abstract}
Background: Dysregulation of the common stress responsive transcription factor ATF3 has been causally linked to many important human diseases such as cancer, atherosclerosis, infections, and hypospadias. Although it is believed that the ATF3 transcription activity is central to its cellular functions, how ATF3 regulates gene expression remains largely unknown. Here, we employed ATF3 wild-type and knockout isogenic cell lines to carry out the first comprehensive analysis of global ATF3-binding profiles in the human genome under basal and stressed (DNA damage) conditions.

Results: Although expressed at a low basal level, ATF3 was found to bind a large number of genomic sites that are often associated with genes involved in cellular stress responses. Interestingly, ATF3 appears to bind a large portion of genomic sites distal to transcription start sites and enriched with p300 and H3K27ac. Global gene expression profiling analysis indicates that genes proximal to these genomic sites were often regulated by ATF3. While DNA damage elicited by camptothecin dramatically altered the ATF3 binding profile, most of the genes regulated by ATF3 upon DNA damage were pre-bound by ATF3 before the stress. Moreover, we demonstrated that ATF3 was co-localized with the major stress responder p53 at genomic sites, thereby collaborating with p53 to regulate p53 target gene expression upon DNA damage.
\end{abstract}

Conclusions: These results suggest that ATF3 likely bookmarks genomic sites and interacts with other transcription regulators to control gene expression.

Keywords: ATF3, ChIP-seq, Enhancer, p300, H3K27ac, p53

\section{Background}

The development of human diseases is often accompanied by changes in the gene expression landscape. Regulated mainly at the transcription level, gene expression is tightly controlled by transcription factors (TF) that bind not only promoters proximal to transcription start sites (TSS), but also distal cis-regulatory elements (i.e., enhancers) that are far removed from TSS $[1,2]$. Genome-wide profiling studies using chromatin immunoprecipitation coupled with

\footnotetext{
*Correspondence: jindan-yu@northwestern.edu; cyan@augusta.edu ${ }^{\dagger}$ Equal contributors

'Department of Medicine, Division of Hematology and Oncology, Northwestern University Feinberg School of Medicine, Chicago, IL, USA

${ }^{2}$ Georgia Cancer Center, Augusta University, Augusta, GA, USA

Full list of author information is available at the end of the article
}

sequencing (ChIP-seq) have identified thousands of functional/active enhancers that are either bound by the transcriptional co-activator p300, or characterized by their association with high levels of H3 K27 acetylation (H3K27ac) [3-5]. These enhancers often carry binding sites for more than one TF, which interact with the basal transcription machinery associated with core promoters to regulate gene transcription [2]. Very often, TFs also recruit chromatin-modifying enzymes to convert the chromatin to a state permissive for transcription. Pioneer transcription factors (e.g., FoxA1, PU.1), for example, are often the first to engage in a regulatory chromatin region upon stimulation, and enhance transcription by remodeling the local chromatin to make it competent for other TFs to bind [6]. 
While global profiling of genomic sites competent for TF binding is imperative for the understanding of TF functions, such work has also become increasingly important for defining disease etiologies, as mutations in cis-regulatory elements are frequently found to be associated with human diseases (e.g., cancer) by wholegenome sequencing studies [7].

Activating transcription factor 3 (ATF3) is a member of the ATF/CREB family of transcription factors involving in many important human diseases including cancer [8-11], atherosclerosis [12], infections [13], cardiac hypertrophy [14], and hypospadias [15]. The contributions of ATF3 to these diseases are often owing to its rapid induction by a wide-range of cellular stresses (e.g., DNA damage, oxidative stress, and endoplasmic reticulum (ER) stress), leading to activation of cellular signaling required for the maintenance of cell homeostasis. Indeed, while it binds and activates the tumor suppressor p53 in response to oncogenic challenges (e.g., DNA damage and Pten inactivation) [11, 16], ATF3 also engages in the immune response by interacting with NF- $\mathrm{kB}$ and repressing expression of proinflammatory cytokines induced by the toll-like receptor 4 [17]. Similarly, ATF3 induced by reactive oxygen species causes high susceptibility to secondary infections by repressing interleukin 6 (IL-6) expression during sepsis-associated immunosuppression [13]. Like other ATF/CREB transcription factors, ATF3 regulates transcription by binding the canonical ATF/CRE cis-regulatory element (5'-TGACGTCA-3') or the similar AP-1 site (5'-TGA(C/G)TCA-3') via its basic region-leucine zipper domain (bZip) [18]. Although an over-simplified model suggests that ATF3 homodimers and heterodimers (with other bZip proteins) repress and induce gene expression, respectively [19], the mechanism by which ATF3 regulates transcription remains largely unknown. Interestingly, although the structures of the bZip domains are highly similar allowing the largely diversified ATF/ CREB proteins to bind the same cis-regulatory elements, the genes regulated by ATF3 are distinct from those controlled by its family members. ATF3 and ATF6, for instance, regulate expression of proapoptotic genes and genes involved in protein folding and ER quality control upon ER stress, respectively [20]. As recent evidence supports that ATF3 engages in a complex protein-protein interaction network involving many TFs and transcription co-regulators $[16,21,22]$, it is likely that the interactions with other nuclear proteins define the genomic sites where ATF3 binds and the transcription programs that ATF3 regulates. Characterization of genome-wide ATF3 binding sites would thus lead to further elucidation of the ATF3 interaction network and a better understanding of how ATF3 regulates expression of disease-associated genes.

In this study, we present the first comprehensive analysis of ATF3 binding profiles in the human genome. We show that ATF3 bound a large portion of active enhancers characterized by p300 binding and enriched with K27 acetylated histone H3 (H3K27ac) under the basal condition where ATF3 was expressed at a very low level. While the expression of genes proximal to these enhancers tended to be regulated by ATF3, ATF3 was co-localized with p53 and regulated p53-target gene expression in response to DNA damage. Our results thus suggest that ATF3 likely bookmarks genes for transcriptional regulation under basal and stressed conditions.

\section{Results \\ Genome-wide mapping of ATF3 binding sites using isogenic cell lines}

To profile global ATF3-binding sites, we first employed a genome-editing approach based on recombinant adenoassociated viruses (rAAV) to generate a cell line in which ATF3 expression was knocked out. Towards this end, we constructed an AAV targeting vector containing left (LA) and right homology arms (RA) flanking the exon 3 of the ATF3 gene, and introduced the vector into HCT116 human colon cancer cells via rAAV infections [23]. Homologous recombination between the homology arms and the ATF3 fragments resulted in the insertion of a selection gene (TK-neo) into an ATF3 allele. A small deletion (22 bp) in the exon 3 was subsequently generated by Cre-mediated excision of the selection gene (Fig. 1a). The same strategy was employed to target the second ATF3 allele, generating a cell line (ATF3-KO) in which ATF3 expression was disrupted. We confirmed that ATF3 was not expressed and ATF3 expression was not induced by camptothecin (CPT) - a DNA-damaging agent - in the knockout cells (Fig. 1b).

We thus subjected the wild-type (ATF3-WT) cells and the knockout cells to chromatin immunoprecipitation using an ATF3 antibody. Precipitated DNAs were then labeled and subjected to next-generation sequencing and sequencing reads were mapped to human genome and analyzed for enrichment. Although ATF3 was expressed at a low level (Fig. 1b, lane 1), we identified 33,681 highconfident ATF3-binding peaks in the sample derived from ATF3-WT cells (Fig. 1c). Out of them, a majority of peaks $(32,058)$ were ATF3 specific, as they were not found in the ATF3-KO cells (Fig. 1c and d). A few examples of ATF3 peaks were shown in Fig. 1e. Of note, like a majority of identified sites, these ATF3 peaks were found only in the ATF3-WT sample but not in the ATF3-KO sample (Fig. 1e). Consistent with an early result that ATF3 represses its own expression [24], we found that ATF3 strongly bound its own promoter (Fig. 1e). Using quantitative PCR (qPCR) to examine samples from an independent ChIP experiment, we confirmed that ATF3 bound to all of the tested genomic sites identified by ChIP-seq (Fig. 1f). Again, ATF3 bound to its own promoter in the ATF3-WT cells but not in the knockout cells (Fig. 1g). 

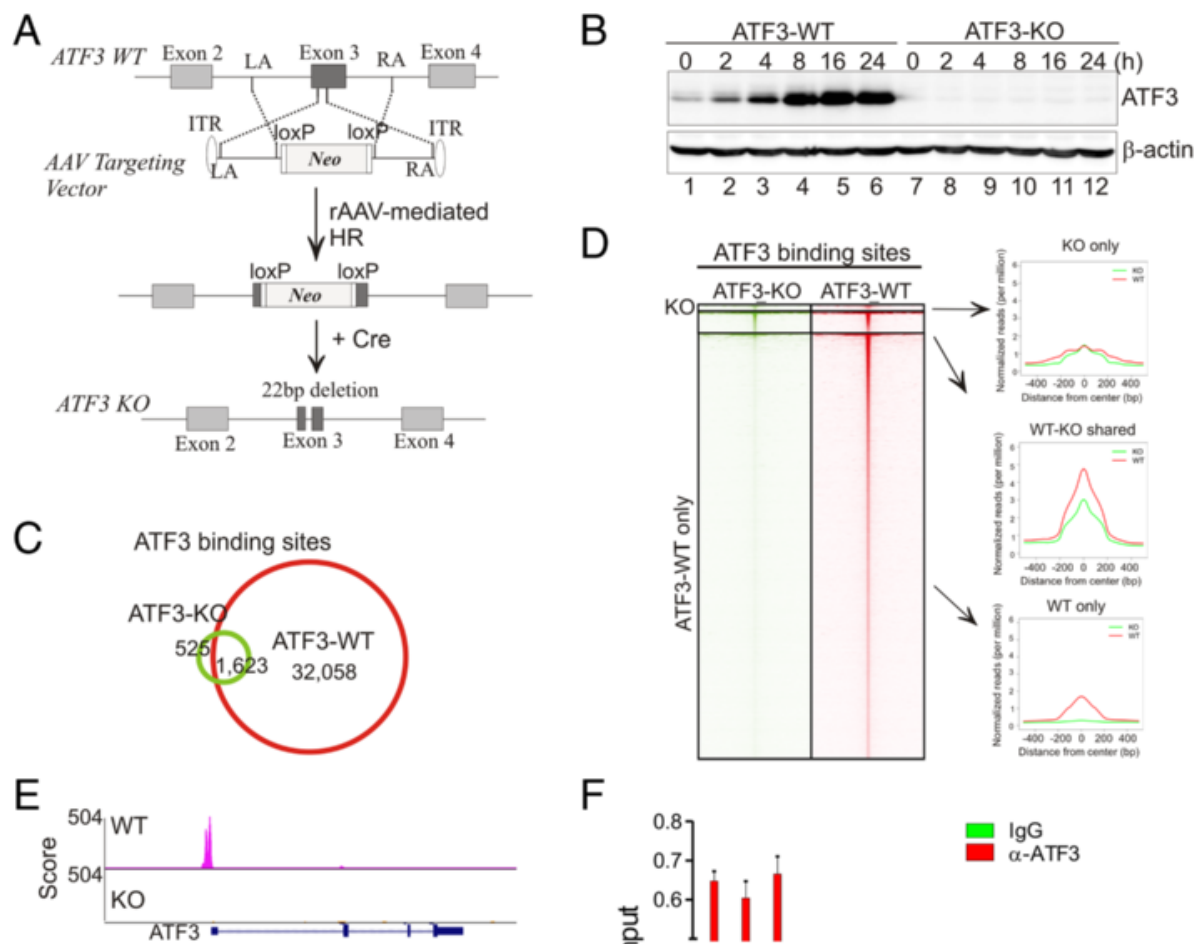

F
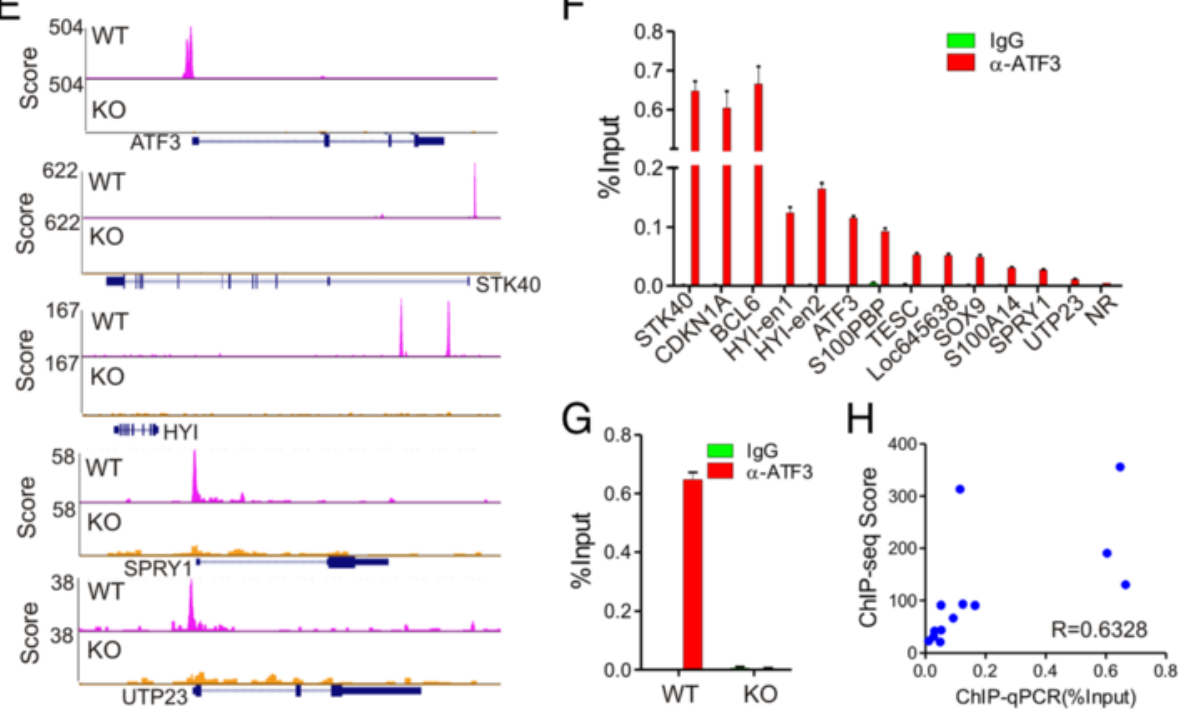

Fig. 1 ATF3 binding profiling using isogenic HCT116 cells. a rAAV-mediated genome editing was applied to generate ATF3-knocked out HCT116 cells. rAAV-mediated homologous recombination led to insertion of the AAV targeting vector into ATF3 exon 3 . A deletion of 22 bp was generated in one ATF3 allele after Cre-mediated excision of the Neo selection gene. LA and RA, left and right homology arms; ITR, inverted terminal repeat; KO, knockout. b ATF3 expression was completely abolished in ATF3-KO cells. Indicated cells were treated with $1.5 \mu$ M of CPT and subjected to Western blotting. c Venn diagram showing ATF3-binding peaks in ATF3 wild-type (ATF3-WT) and knockout (ATF3-KO) cells. d Heatmap and intensity plots showing ATF3 peaks in ATF3 WT and KO cells. e Representative genome browser views of ATF3 peaks. ATF3 peaks near ATF3, STK40, HYI, SPRY1, and UTP23 were shown for both ATF3-WT and KO cells. $\mathbf{f}, \mathbf{g}$ ChIP-qPCR was used to validate ATF3 binding to representative genome sites that were referred to as the names of their annotated genes. NR, no-binding control region. Error bars represent SD for three replicate measurements. $\mathbf{h}$ The binding intensity determined by independent ChIP-qPCR assays was correlated with ChIP-seq scores of peaks tested in (f) and (g)

The strengths of ATF3 binding to these sites measured by ChIP-qPCR were well correlated with the ChIP-seq scores $(R=0.6328)$, demonstrating high reproducibility and reliability of our ChIP-seq data.

\section{Global ATF3-binding profile and motif analysis}

The 32,058 ATF3-specific peaks were annotated to 10,262 unique genes. We analyzed the distribution of these binding sites relative to TSS in the human genome. Consistent with the ATF3's role as a transcription factor, about one fifth $(19.4 \%)$ of the ATF3 peaks were localized in promoters, which was defined as regions that were $\pm 2 \mathrm{~kb}$ surrounding TSS (Fig. 2a). Given that only a small portion of DNA in the whole genome can be defined as promoters, these results indicate that ATF3 were enriched in promoters. However, ATF3 also bound 


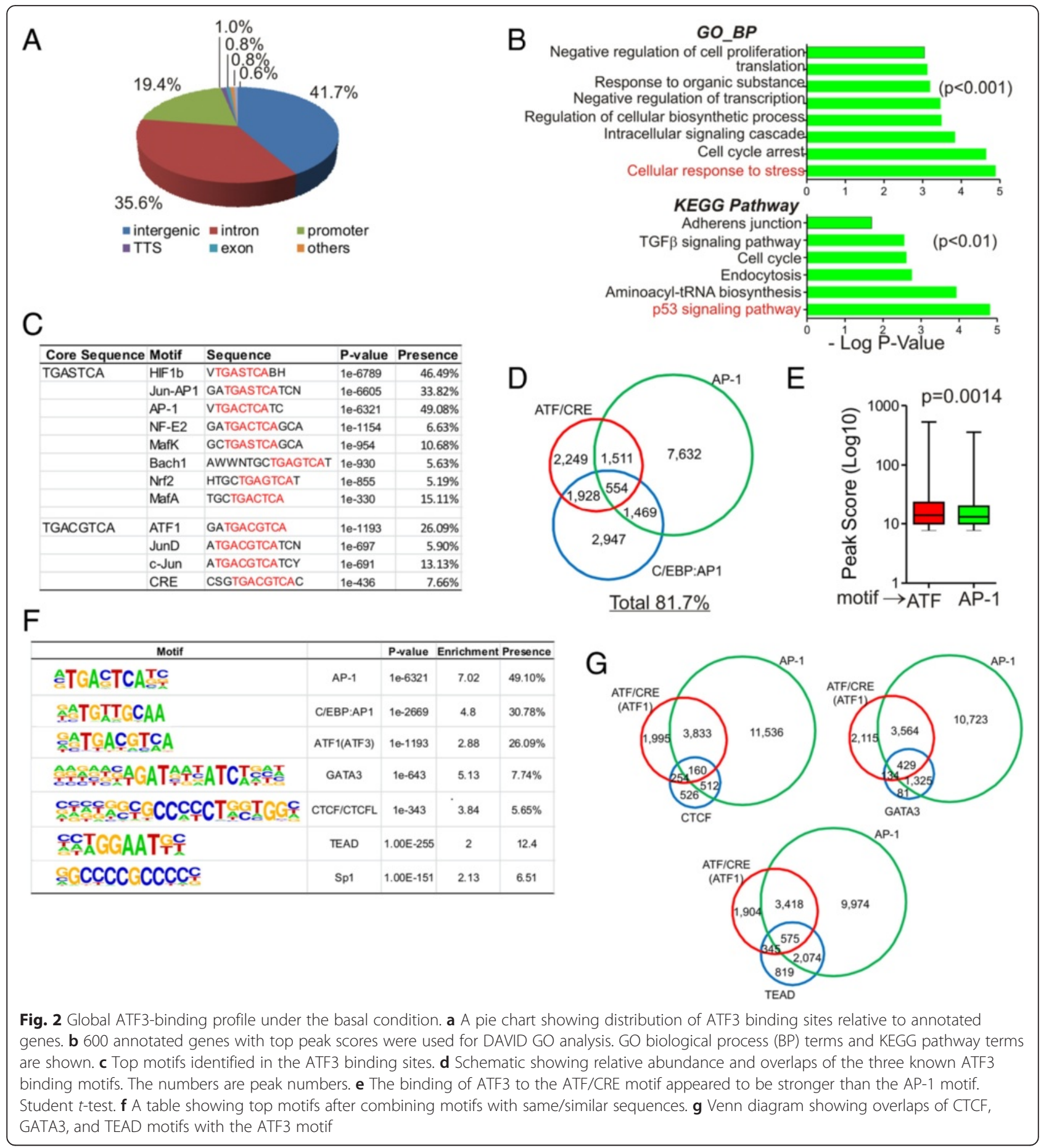

genomic regions far removed from TSS (Fig. 2a), suggesting that ATF3 also likely regulates transcription via long-range interactions. Gene Ontology (GO) analysis of the top 600 annotated genes with high binding scores revealed that ATF3 preferably bound to regulatory elements for genes involving in biological processes such as cellular response to stress, cell cycle arrest and intracellular signaling cascade, as well as pathways such as p53 signaling pathway (Fig. 2b). Interestingly, "cellular response to stress" and "p53 signaling pathway" turned out to be the top GO terms for the ATF3-bound genes, consistent with the well-established roles that ATF3 plays in regulating cellular stress responses and the p53 pathway $[16,18]$. 
We also searched the ATF3 binding sites for known TF binding motifs using the Homer de novo motif discovery software. A total of 140 motifs were identified with a p value smaller than 0.01 . With only one exception (CEBP:AP1 motif), the top 12 identified motifs contained either the canonical ATF/CRE sequence (i.e., 5'TGACGTCA-3') or the AP-1 sequence (i.e., 5'-TGASTCA3', $\mathrm{S}=\mathrm{C} / \mathrm{G}$ ) (Fig. 2c). As C/EBP harbors a bZip domain that can mediate dimerization with other bZip proteins including ATF3 [25], it might be that ATF3 bound the CEBP:AP1 motif through dimerization with C/EBP. Overall, $81.7 \%$ of ATF3 binding sites contain an element predicted to be bound by ATF3 - collectively referred to as the ATF3 motif hereafter (Fig. 2d) - suggesting that ATF3 directly binds genomic DNA in most cases. Interestingly, although more ATF3 peaks contained the AP-1 motif (Fig. 2e), the binding affinity of ATF3 to the canonical ATF/CRE element appeared to be higher than that for ATF3 binding to the AP-1 element (Fig. 2e). In addition to these known ATF3 binding motifs, other top ATF3 binding motifs (i.e., Enrichment > 2) include GATA3, CTCF, TEAD, and Sp1, which was presented in $7.7 \%, 5.6 \%, 14.8 \%$, and $6.5 \%$ of ATF3 peaks, respectively (Fig. 2f). Although these ATF3binding peaks often contain a known ATF3 motif (Fig. 2g), ATF3 might also bind these motifs through interacting with corresponding TFs. Indeed, ATF3 has been shown to interact with $\mathrm{Sp} 1$ [26].

\section{ATF3 globally binds active enhancers enriched with p300 and H3K27ac}

As ATF3 bound genomic sites far removed from TSS, we sought to determine whether these sites are coincided with active enhancers that are often marked by p300 binding and flanked with high levels of H3K27ac [3-5]. Towards this end, we acquired p300, H3K27ac, H3K4me1, and H3K4me3a ChIP-seq data (HCT116 cells) from the Gene Expression Omnibus (GEO) database GSE51176 and GSE38447 [27, 28]. We first examined the ATF3 peaks in the Genome Browser, and found that ATF3 bound to many sites that were also bound by $\mathrm{p} 300$ and flanked by regions with high levels of H3K27ac (Fig. 3a), suggesting that ATF3 bound to active enhancers. Indeed, unbiased statistics analysis revealed that up to $27.5 \%$ of ATF3 peaks were overlapped with $\mathrm{p} 300$ peaks, and $37 \%$ of p300 peaks were bound by ATF3 (Fig. 3b). Intensity plots also show that p300 was globally co-localized with ATF3 and that the H3K27ac histone marker surrounded the ATF3/p300 peaks as expected (Fig. 3c). We segregated the ATF3 peaks into proximal sites (within $2 \mathrm{~kb}$ ) and distal sites $(>2 \mathrm{~kb})$ based on their distances to TSS, representing H3K4me3-enriched promoters and H3K4me1-enriched enhancers, respectively (Fig. 3d). The intensity plots revealed that it was the distal sites, but not the proximal sites, that were coincided with p300 binding events (Fig. 3d). Using qPCR, we validated that p300 bound to all of the tested ATF3 binding sites in an independent ChIP experiment (Fig. 3e). Similarly, the enrichment of H3K27ac in these ATF3 sites was also validated (Fig. 3f). Of note, as p300 is not the only enzyme that can acetylate $\mathrm{H} 3$ at the K27 site, the H3K27ac level was not strictly correlated with the p300 level in some genome sites. Taken together, our results have revealed that a large portion of ATF3 bound active enhancers.

\section{ATF3-regulated gene expression correlates with ATF3 enhancer binding}

An interesting question surfaced as to how ATF3 binding to genomic sites regulates gene expression. To address this question, we subjected the ATF3-wildtype and knockout cells to cDNA microarray assays. Although ATF3 bound to 10,262 genes, only 1,087 unique genes, including several known ATF3 targets (i.e., ASNS) [29], were differentially expressed between the WT and $\mathrm{KO}$ cells $(\mathrm{FDR}<0.05$, Additional file 1: Figure S1A and S1B). Among these genes, $630(60 \%)$ were bound by ATF3 and thus more likely to be directly regulated by ATF3 (Fig. 4a). Roughly equal numbers of genes was either activated or repressed by ATF3 (Fig. 4a), suggesting that ATF3 can function as both a transcription repressor and a transcription activator. In line with the reported tumor suppressor role in colon cancer [30, 31], ATF3 appeared to induce expression of genes involving in mitosis and stress responses while repressing genes regulating vasculature development, migration, and apoptosis (Additional file 1: Figure $\mathrm{S} 1 \mathrm{C}$ ). We validated 7 differentially-expressed genes by quantitative RT-PCR (Fig. 4b) and their binding by ATF3 by independent ChIPqPCR assays (Fig. 4c and d). Interestingly, although ATF3 were often reported to regulate gene expression by binding to a ATF3 motif localized in promoters, only $15 \%(95 / 630)$ of the ATF3-regulated genes identified herein were bound by ATF3 exclusively at their promoters (proximal genomic regions) (Fig. 4e). The rest of genes either were bound by ATF3 exclusively at distal regions (57 \%, or $361 / 630)$, or at both promoters and distal regions (28\%, or 95/630) (Fig. 4e). These results suggest that ATF3 could regulate gene expression by binding to distal cis-regulatory elements localized in active enhancers. Indeed, except $M A L 2$, all other validated ATF3-target genes were bound by ATF3 at distal regions overlapped with p300 peaks (Fig. 4f). Of the 535 genes containing distal ATF3-binding sites, 354 (66.2 \%) were associated with active enhancers enriched with p300 and bound by ATF3 (Fig. 4g). Interestingly, ATF3-repressed genes appeared to be more likely to harbor distal ATF3 regulatory elements than ATF3-activated genes (Additional file 1: Figure S1D), although the TF motifs contained in the ATF3-binding sites in these two groups of genes were similar (Additional file 1: Figure S1E). 


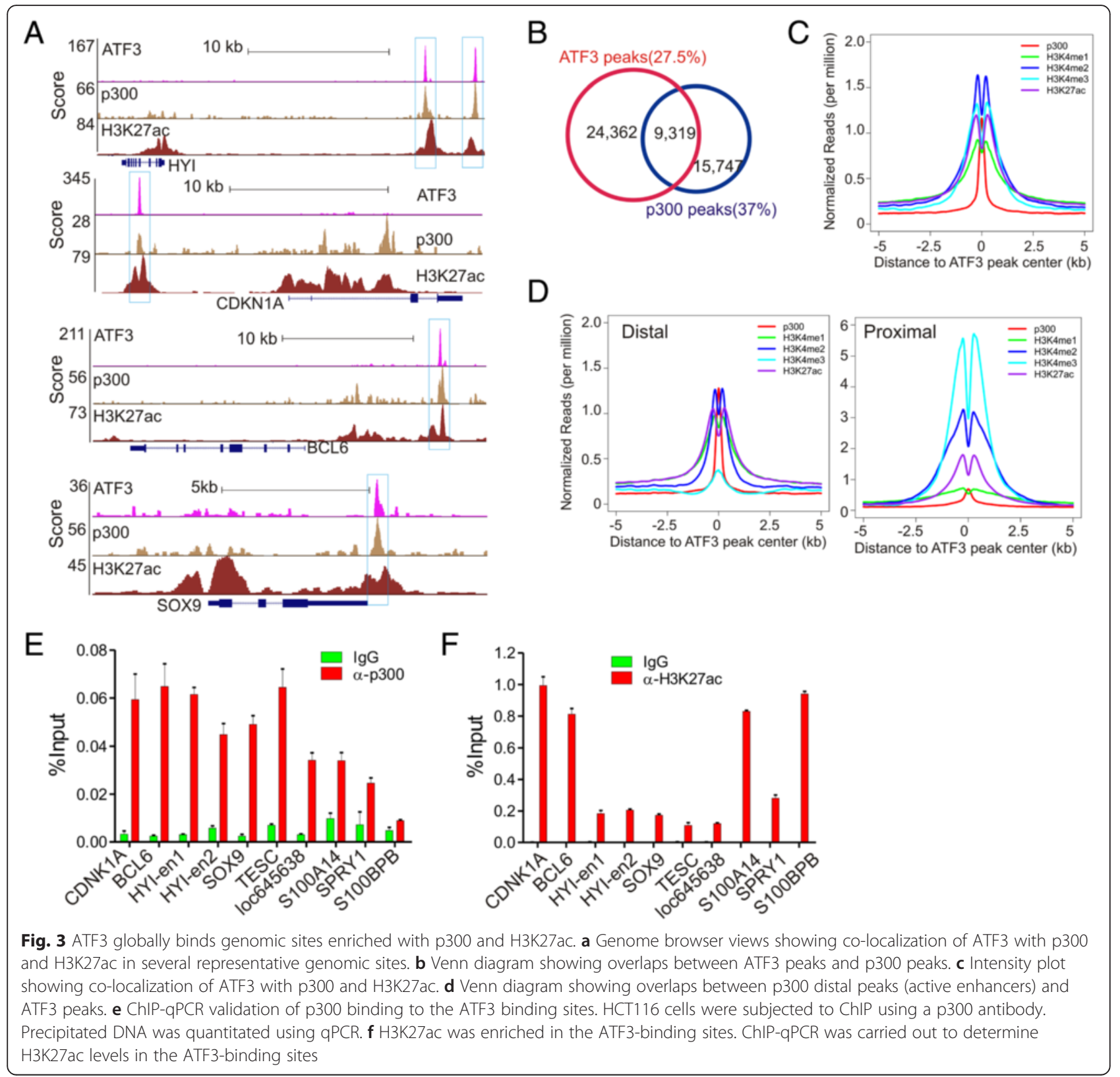

\section{DNA damage alters the ATF3-binding landscape for gene regulation}

As a common stress sensor, ATF3 may regulate cellular stress responses by altering the gene expression landscape. To understand how cellular stresses alter genome-wide ATF3 binding profile for transcriptional regulation, we subjected HCT116 cells treated with CPT for ChIP-seq assays. As CPT could increase the ATF3 expression level (Fig. 1b) [32], it was not surprising that the DNAdamaging treatment increased the number of ATF3binding sites to 70,231 (Fig. 5a) - one fold more than that under the basal condition. However, we found that a large number of sites $(7,172,21.3 \%)$ bound by ATF3 under the basal condition were not detected after the CPT treatment
(Fig. 5a and b, "WT-only"). ATF3 bound these sites more weakly than the remained sites (Fig. 5b, "WT-only" vs. "Shared" peaks, $p=7.46 \mathrm{e}-05)$. Of the "shared" peaks, DNA damage increased ATF3 binding to 13,253 sites but decreased its binding to the rest 13,256 sites (Additional file 1: Figure S2A). Interestingly, while the CPT-increased sites appeared to be bound by ATF3 more strongly than the CPT-decreased sites under the basal condition (Fig. 5c), the increased sites were also often bound by p300, or enriched with H3K4me1, suggesting that DNA damage promoted ATF3 to bind to active enhancers (Fig. 5c). In contrast, CPT tended to decrease ATF3 binding to those sites localized in promoters and thus often flanked by a high level of H3K4me3 [33] (Fig. 5c). 

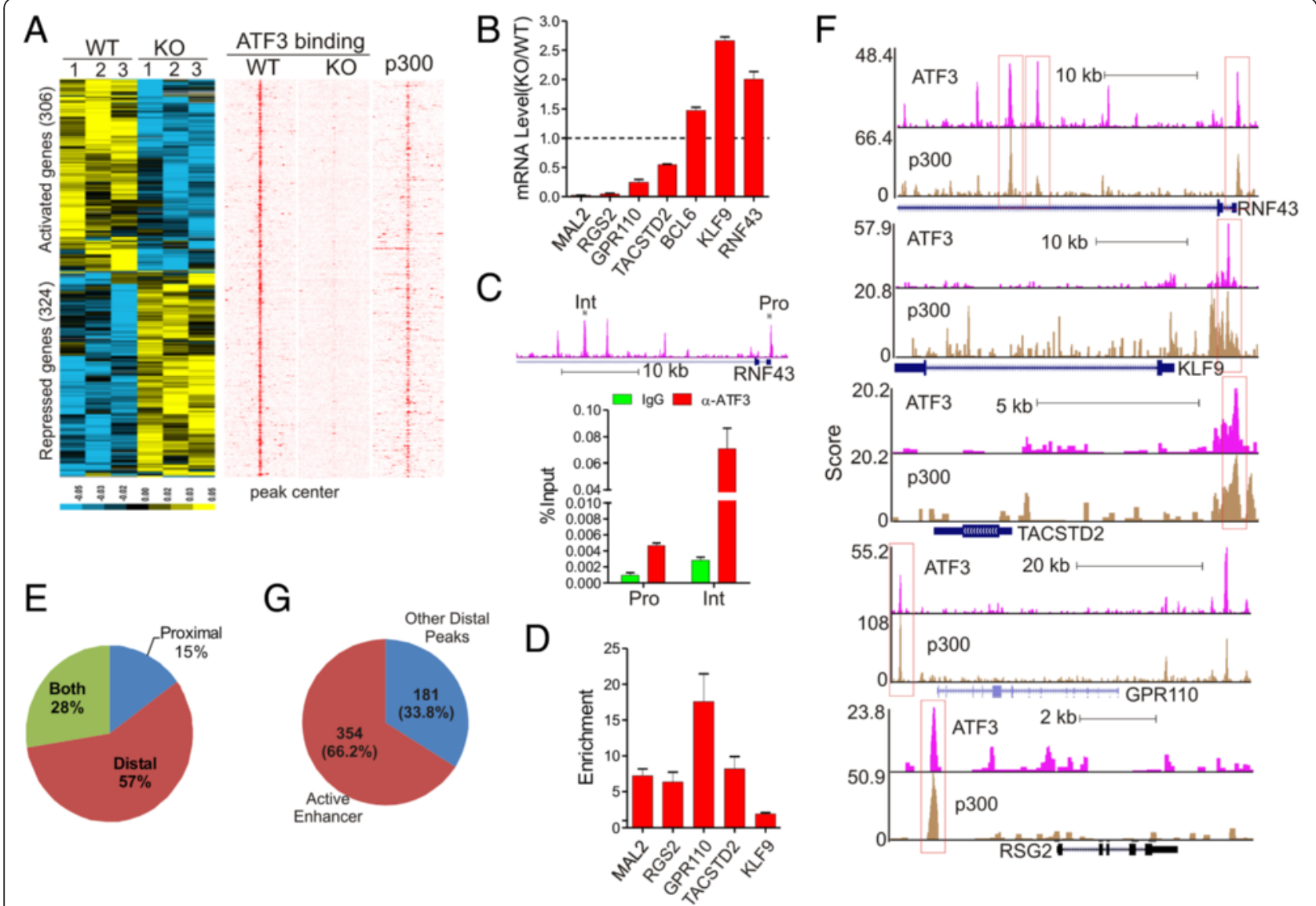

Fig. 4 Binding of ATF3 to active enhancers correlates with ATF3-regulated gene expression. a Heatmaps showing ATF3-regulated genes, and their binding by ATF3 and p300. $\mathbf{b}$ qRT-PCR validation of genes differentially expressed between ATF3-wildtype and knockout cells identified by microarray. c, $\mathbf{d}$ Validation of ATF3 binding to differentially-expressed genes by ChIP-qPCR. e ATF3 was localized in regions distal to TSS (>2 kb) of differentiallyexpressed genes. $\mathbf{f}$ Representative genome browser views of co-localization of ATF3 and p300 in ATF3-regulatd genes. $\mathbf{g}$ ATF3 was localized in active enhancers of ATF3-regulated genes. Error bars represents SD

Consistent with these observations, although DNA damage did not significantly change the overall genome distribution and motif composition of the ATF3 binding sites (Additional file 1: Figure S2B and S2C), it promoted ATF3 to bind to the sites distal to TSS (Fig. 5d). Similarly, DNA damage increased the number of sites bound by both ATF3 and p300, and the number of these ATF3-bound active enhancers was increased from $37 \%$ under the basal condition to $57.6 \%$ upon stress (Fig. 5e). Interestingly, the new sites bound by ATF3 after DNA damage ("CPT only" in Fig. 5b) had weaker ATF3-binding affinities than the sites bound by ATF3 under the basal condition $(p=1.73 \mathrm{e}-07$, comparing "CPT only" vs "Shared" peaks in Fig. 5b), but had stronger affinities than those lost peaks $(p=0.000345$, "CPT only" vs "WT only", Fig. 5b). Our results thus suggest that ATF3 not only increased its level, but also altered its genome binding in response to DNA damage.

We next addressed the question as to what changes in gene expression the altered ATF3-binding would cause under the DNA damage condition. Treating HCT116 cells with CPT for $4 \mathrm{~h}$ resulted in an increase in expression of 733 genes and a decrease in expression of 1095 genes (fold $>1.5, p<0.05$ ) (Fig. 5f). 1,300 (71.1\%) of these altered genes were bound by ATF3 after DNA damage (Fig. 5g), and thus were more likely regulated by ATF3. Interestingly, $82.9 \%$ of ATF3-bound, CPTregulated genes were also bound by ATF3 before the cells were treated with CPT (Fig. 5g), suggesting that ATF3 were pre-loaded on the genomic sites for gene regulation under stressed conditions. However, stressed ATF3 appeared to bind these sites more strongly than the quiescent protein (Fig. 5h). Given that CPT equally increased or decreased ATF3 binding on the "shared" sites (see above), these results indicate that DNA damage selectively promoted ATF3 to bind to genomic sites associated with regulated genes.

To further determine the relationship between ATF3 binding and gene regulation under the stressed condition, we analyzed the gene expression data for ATF3 knockout cells, and generated a curated list of 93 genes 


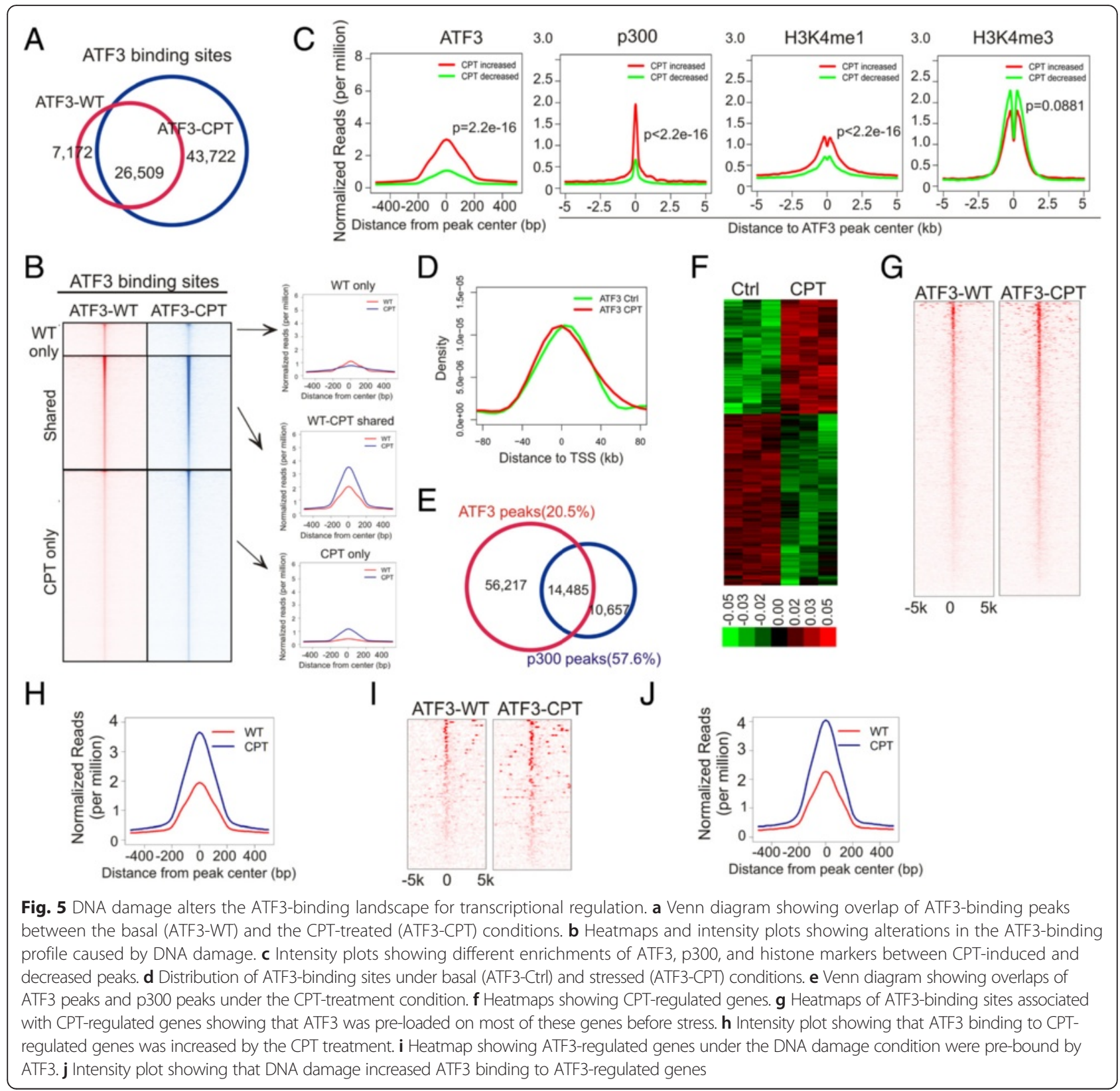

that were judged, with high confidence, as ATF3regulated genes in response to DNA damage (Additional file 1: Figure S2D), based on (1) that fold changes before and after the CPT treatment were significantly different $(p<0.05$, paired $t$-test) between ATF3-wildtype and -knockout cells, (2) that the genes bound by ATF3 with a small binding score $(<10)$ and thus more likely to be derived from experimental errors were excluded. Once again, while $82(88.2 \%)$ of these genes had already been bound by ATF3 under the basal condition, CPT further increased ATF3 binding to these regulated genes, regardless whether their expression was induced or repressed by CPT (Fig. 5i and j). Interestingly, about a half (43, or $46 \%$ ) of these genes contained one or more active enhancers that were bound by both p300 and ATF3 (Fig. 5i), consistent with our previous conclusion that ATF3 can bind to active enhancers to regulate gene expression.

\section{ATF3 collaborates with p53 in regulating target gene expression}

p53 is a master transcription factor that transactivates genes (e.g., CDKN1A and BBC3, best known as $p 21$ and PUMA, respectively) essential for driving cellular responses (e.g., cell cycle arrest and apoptosis) to DNA damage [34]. As ATF3 can bind p53 [16] and we also found that ATF3-bound genes engage in the p53 signaling pathway (Fig. 2c), we 
sought to determine how ATF3 interacts with p53 at genomic sites to regulate gene expression in response to CPTinduced DNA damage. We first profiled global p53 binding by subjecting CPT-treated HCT116 cells to ChIP-seq analysis. We identified 1,412 p53-binding peaks (Fig. 6a), a number which was low but within the same range (from 743 to 4,785$)$ as other reports [35-37]. These identified binding sites included 3 previously-characterized p53-

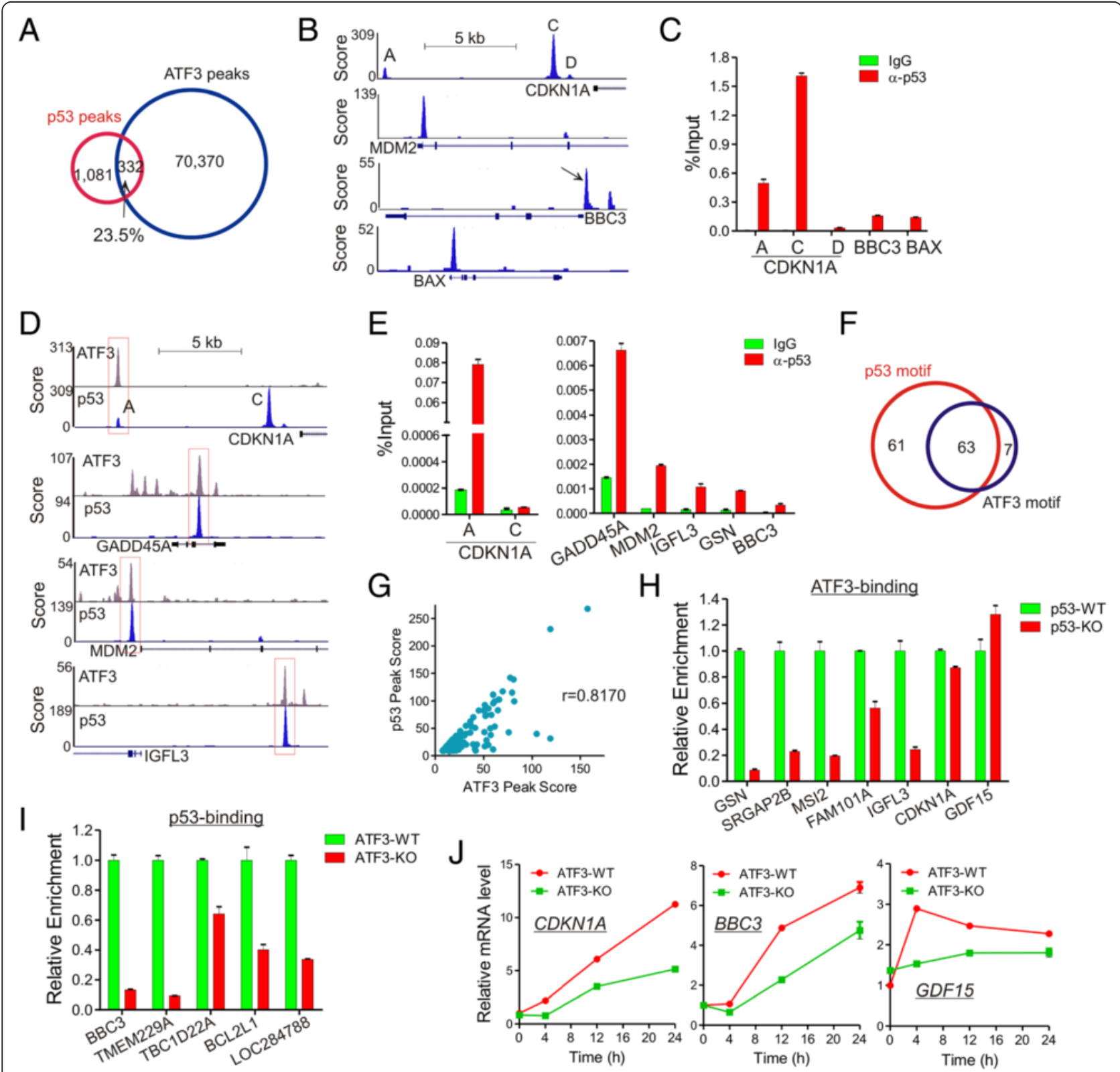

Fig. 6 Co-localization of ATF3 and p53 in genomic sites regulates gene expression in the DNA damage response. a Venn diagram showing the overlap between ATF3 peaks and p53 peaks under the DNA damage condition. b Genome browser views of p53 binding to several well-characterized p53 target genes. c Binding of p53 to indicated sites was validated by independent ChIP-qPCR assays. $\mathbf{d}$ Genome browser views of co-localization of ATF3 and p53 in representative genomic sites. e ATF3 and p53 were co-localized in genomic sites as demonstrated by re-ChIP assays. HCT1 16 cells treated with $1.5 \mu \mathrm{M}$ of CPT for $4 \mathrm{~h}$ were first subjected to ChIP using the ATF3 antibody. The chromatin precipitated by the ATF3 antibody was then eluted from agarose beads, and subjected to the second round of ChIP using the p53 antibody. qPCR assays were used to quantitate re-ChIPed DNA. f Venn diagram showing the overlap of p53-binding sites containing the p53 motif or the ATF3 motif. $\mathbf{g}$ The ATF3 peak score correlated with the p53 peak score in the sites co-localized by ATF3 and p53. h ATF3 binding was often decreased in p53-knockout cells. p53-wildtype and knockout (p53-KO) HCT116 cells were subjected to ChIP-qPCR to measure binding of ATF3 to the indicated sites. i p53 binding was decreased in ATF3-knockout cells. ATF3-wildtype and knockout (ATF3-KO) HCT1 16 cells were subjected to ChIP-qPCR to measure binding of p53 to the indicated sites. $\mathbf{j}$ Expression of p53 target genes was repressed in ATF3-KO cells. Indicated cells were treated with $1.5 \mu \mathrm{M}$ of CPT for qRT-PCR assays. ATF3 binding to these genes before and after CPT treatments in ATF3-WT cells were shown in Additional file 1: Figure S3 
binding sites in the CDKN1A enhancer and promoter regions (site A, C and D, respectively) (Fig. 6b) [35], and sites localized in the promoters of well-characterized p53 target genes $M D M 2, B B C 3$ and $B A X$ (Fig. 6b). These p53-binding sites were validated by independent ChIP-qPCR assays (Fig. 6c). Consistent with the notion that ATF3 is a p53 regulator [16], we found that ATF3 bound to $23.5 \%$ (332) of p53-binding sites (Fig. 6a), including the CDKN1A site A (but not site $\mathrm{C}$ and $\mathrm{D}$ ), and the sites associated with GADD45A, MDM2 and IGFL3 (Fig. 6d). Using re-ChIP assays, we confirmed that ATF3 was co-localized with p53 at Site A, but not Site C, of CDKN1A, and other tested genomic sites associated with GADD45A, MDM2, IGFL3, GSN, and BBC3 (Fig. 6e). Of these ATF3/p53 co-localized sites, 61 only carried a p53 motif, 7 only carried an ATF3 motif, and 63 harbored both motifs (Fig. 6e; Additional file 2: Table S1). Given that ATF3 can directly bind p53 [16], co-localization of ATF3 with p53 at genomic sites might be owing to p53-mediated recruitment of ATF3 to sites containing the p53 motif, and/or ATF3-mediated recruitment of p53 to sites harboring the ATF3 motif. Indeed, we found a strong correlation between the ATF3-binding score and the p53 peak score at these genomic sites $(r=0.8170$, Fig. 6g). Moreover, p53 depletion dramatically impaired ATF3 binding to 5 out of 7 tested p53-motif-only sites (Fig. 6h). Of note, although p53 was previously shown to be required for ATF3 induction by DNA damage caused by $\gamma$ irradiation [38], we did not see decreased ATF3 expression in p53-knockout cells under our experimental condition (data not shown). The reason why p53 knockout did not decrease ATF3 binding to the CDKN1A Site A and the GDF15 p53-binding site that lacked the ATF3 motif was unclear, but other TFs might recruit ATF3 to these sites. Interestingly, p53 binding to the sites containing only the ATF3 motif was significantly decreased by ATF3 knockout as well (Fig. 6i), suggesting that ATF3 could also recruit p53 to genomic sites that do not contain a p53 motif. Thus, the ATF3-p53 interaction might expand the list of genes that can be regulated by p53. Interestingly, $19.5 \%$ (58/297) of the ATF3/p53 co-localized sites, including the site associated with $C D K N 1 A, B B C 3$ and $G D F 15$, were also enriched with p300, suggesting that many of these sites were active enhancers and thus the ATF3-p53 interaction on genomic sites were likely functional. Indeed, we demonstrated that knockout of ATF3 expression impaired CPT-induced $C D K N 1 A, B B C 3$, and GDF15 expression (Fig. 6j). Therefore, our results indicate that ATF3 could interact with p53 at genomic sites thereby regulating gene expression in the DNA damage response.

\section{Discussion}

It is often shown that ATF3 binds the ATF/CRE cis-acting element localized in gene promoters and regulate expression of genes associated with human diseases [12-14]. We carried out this study in light of the fact that a genomewide ATF3-binding profile in the human genome was lacking. Employing engineered ATF3-knockout cells as the specificity control, we identified 33,681 specific ATF3binding sites across the human genome under the basal condition. Although this number was surprisingly large given that the basal ATF3 expression level was low, it was comparable to 22,521 sites identified in mouse dendritic cells [39]. As $81.7 \%$ of the ATF3-binding sites contained a known ATF3 motif (Fig. 2e) [40], ATF3 might directly bind a majority of these sites. It was thus likely that the low level of constitutively-expressed ATF3 was sufficient to bind most of available sites in the genome. Interestingly, ATF4, a family member sharing the same binding motif with ATF3, binds only 1,210 sites in the mouse genome [39]. While this difference might be owing to different DNA-binding affinity, interactions with other transcription regulators could poise ATF3 for a higher level of genome binding. The latter possibility is supported by the fact that ATF3 differs from ATF4 in its ability of interacting with other proteins [25]. It is worth noting that the ATF3 genome-occupancy level is lower than that of pioneer factors, which often bind more than 50,000 genomic sites [39], but significantly higher than that of most of gene-specific TFs (e.g., p53) that generally occupy a few thousands of genomic sites (Fig. 6a). It is thus tempting to hypothesize that ATF3 serves as a molecular beacon, or "primer factor", that binds genomic sites subsequent to binding of pioneer factors, and directs other TFs or transcription co-regulators to appropriate genomic sites upon stimulation [39]. This hypothesis was partly supported by the findings that ATF3 directly interacts with many TFs (e.g., p53, p63, AR, Sp1) $[16,21,26,41]$ and histone modifying enzymes (e.g., Tip60 and HDAC) [17, 22]. Importantly, while the GO analysis revealed that the ATF3-bound genes were associated with cellular response to stress under the basal condition (Fig. 2c), we found that the genes whose expression was regulated by DNA damage were often pre-bound by ATF3 (Fig. 5g). Thus, like the transcription factor p63 [42], ATF3 might bookmark genes for transcriptional regulation. In this regard, it is likely that ATF3 recruits diverse sets of TFs to genomic sites pre-bound by ATF3 upon varying stimuli, thereby regulating gene expression and mounting rapid, appropriate responses to varying cellular stresses. However, DNA damage-induced changes in ATF3 binding were more dynamic than what the "primer-factor" hypothesis suggests [39]. DNA damage not only increased the number of ATF3 binding sites by 1 fold, but abolished up to one-fifth of the basal binding events (Fig. 5b). In addition, CPT increased ATF3 binding to some genomic sites but decreased its binding to almost equal numbers of other sites. While stress-induced loss of genomic binding has also been reported for other stress-inducible TFs (e.g., JunB) [39], the decrease in ATF3 binding to a substantial number of 
genomic sites argues against the notion that the dynamic changes in ATF3 binding was a mere consequence of elevated ATF3 expression induced by DNA. As DNA damage can alter chromatin structure [43-45], it might allow access of some genomic sites to, while shielding other sites from, ATF3. Interestingly, the CPT treatment appeared to promote ATF3 to bind to sites distal to TSS (Fig. 5d). While the exact mechanism remains elusive, it might be that the epigenetic environments where the distal sites reside are favorable for TF binding. Indeed, these distal sites often coincide with p300/H3K27ac-enriched active enhancers (Fig. 3d), which are known to have lower nucleosomal density [5].

Like other TFs [36, 42], binding of ATF3 to the regulatory region of a gene did not always result in a change in gene expression. Indeed, although ATF3 bound more than 10,000 genes, a complete loss of ATF3 expression only altered expression of a small number of genes under both the quiescent and the stressed condition. While RNA-based assays (e.g., microarray and RNA-seq) may not serve as accurate measurements of transcription activity [42], other TFs capable of binding the same motifs (e.g., JunB) [39] might compensate for ATF3 loss. Interestingly, the ATF3-binding sites often contained motifs of other TFs in addition to the ATF3 motif (Fig. 2), suggesting that ATF3 might act in concert with other TFs to regulate gene expression. Our results also indicate that ATF3 can activate or repress gene expression depending on gene context. While the location and motif composition of the ATF3-binding site did not appear to determine whether ATF3 activates or represses gene expression (Additional file 1: Figure S1D and S1E), it is very likely that the epigenetic environment surrounding the ATF3-binding sites determine the availability of transcription co-activators (like Tip60), or transcription co-repressors (e.g., HDAC), which consequently transactivate or repress expression of ATF3bound genes. Thus, the early notion that ATF3 homodimers and heterodimers respectively repress and activate transcription appears oversimplified and misleading.

An important finding from this study is that ATF3 bound to $37 \%$ of genomic sites that were bound by p300 and characterized by high levels of H3K27ac under the basal condition (Fig. 3b). These genomic sites are defined as active enhancers and have been shown to contain functional regulatory elements that drive proximal gene expression during embryonic development $[3,4]$. Interestingly, DNA damage increased the percentage of active enhancers bound by ATF3 to $57.6 \%$. Moreover, although ATF3 binding alone was not sufficient to regulate transcription, most of genes regulated by ATF3 appeared localized proximal to ATF3bound active enhancers (Fig. 4). This strong correlation between TF binding to active enhancers and the regulation of gene expression was not without precedent. The transcription factor p63, for instance, was recently shown to bind H3K27ac-enriched active enhancers, and the binding correlates with dynamic gene expression regulated by p63 during epidermal differentiation [42]. As active enhancers often contain a cluster of motifs allowing for binding by multiple TFs, it is likely that these TFs collaboratively interact with the basal transcription machinery in core promoters to regulate gene expression. Therefore, the observed correlation between enhancer binding and transcriptional regulation is consistent with our notion that ATF3 needs to cooperate with other TFs to regulate gene expression.

The tumor suppressor p53 drives a transcription program for eliciting diverse cellular responses to DNA damage. Previously, we reported that ATF3 can activate p53 by binding and directly blocking its ubiquitination [16]. We also found that ATF3 can induce p53 activation by promoting the activity of a histone acetyltransferase Tip60 and the subsequent activation of ATM [22]. In this study, we revealed an additional mechanism by which ATF3 regulates p53, i.e., co-localization with p53 at genomic sites. Indeed, we found that ATF3 was colocalized with p53 at more than $20 \%$ of p53-binding sites identified by ChIP-seq (Fig. 6a). As ATF3 can interact with p53 [16], such co-localization might be a consequence of p53-mediated ATF3 recruiting (Fig. 6h), or vice versa (Fig. 6i). On the other hand, some colocalized genomic sites contained both the p53 and the ATF3 motif, and thus could be bound by p53 and ATF3 simultaneously. Regardless, close proximity between ATF3 and p53 at genomic sites might directly alter p53 conformation thereby regulating the p53 transcriptional activity (Fig. 6j). Our results are supported by a recent report, which carried out ATF3 ChIP-chip assays and shows binding of ATF3 to promoters of many known p53 target genes [46]. However, Our study indicates that a large number of co-localized sites were far beyond promoter regions [47] and were also often bound by p300. Therefore, the genomic co-localization of ATF3 and p53 serves as an additional mechanism for fine tuning p53 activity in the DNA damage response.

\section{Conclusions}

Our results indicate that ATF3 likely preoccupies genomic sites regulatory for genes involved in the cellular stress response, and thus bookmarks these sites for transcriptional regulation under basal and stressed conditions.

\section{Methods}

Cell culture and generation of ATF3-knockout cells

HCT116 wild-type and p53-knockout cells (obtained from Bert Vogelstein) were cultured in McCoy's 5A medium supplemented with $10 \%$ fetal bovine serum. 
H1299 cells and 293 T cells were cultured in RPMI 1640 and DMEM medium, respectively. We knocked out ATF3 expression in HCT116 cells using a rAAV-based approach [23]. Briefly, left and right homology arms flanking a small region (22 bp) in the exon 3 of ATF3 were amplified by PCR, and sequentially ligated into pAAV-TK-Acceptor [23] via restriction enzyme digestion. The resulted plasmid was then transfected into AAV-293 cells for rAAV packaging using the AAV Helper-free System (Agilent) following the manufacturer's protocol. For viral infections, HCT116 cells in $60 \mathrm{~mm}$ dishes were incubated with $2 \mathrm{ml}$ of viral supernatant overnight, followed by re-suspension in medium containing $500 \mu \mathrm{g} / \mathrm{ml}$ of G418 for selection. Genomic DNAs were then prepared from resistant single clones as describe previously [48], and used for PCR to identify targeted clones. To remove the inserted selection gene, targeted clones in 24-well plates were transfected with a Cre-expression plasmid. Single clones regaining G418 sensitivity were accordingly identified, and subjected to the 2nd round of genome editing to knock out the 2nd ATF3 allele as describe above. The sequences of primers used in this report are available upon request.

\section{Chromatin immunoprecipitation}

Chormatin immunoprecipitation was performed essentially as described previously [49]. Briefly, cells $\left(2 \times 10^{7}\right)$ treated with or without $1.5 \mu \mathrm{M}$ of $\mathrm{CPT}$ for $4 \mathrm{~h}$ were cross-linked with $1 \mathrm{mM}$ of di(N-succinimidyl) glutarate (DSG) for $45 \mathrm{~min}$, followed by $1 \%$ formaldehyde for $10 \mathrm{~min}$ at room temperature. After treating with $0.125 \mathrm{M}$ of glycine for $5 \mathrm{~min}$, cells were resuspended in $10 \mathrm{ml}$ of Solution I (10 mM Hepes-KOH, pH7.5, $10 \mathrm{mM}$ EDTA, $0.5 \mathrm{mM}$ EGTA, and $0.75 \%$ Triton X-100), and incubated at $4{ }^{\circ} \mathrm{C}$ for $10 \mathrm{~min}$. Cells were further incubated with $10 \mathrm{ml}$ of Solution II (10 mM Hepes-KOH, pH7.5, $200 \mathrm{mM} \mathrm{NaCl}, 1 \mathrm{mM}$ EDTA, and $0.5 \mathrm{mM}$ EGTA) at $4{ }^{\circ} \mathrm{C}$ for 10 min before lysed in cold FA lysis buffer (50 mM Hepes-KOH, pH7.5, $140 \mathrm{mM} \mathrm{NaCl}$, $1 \mathrm{mM}$ EDTA, $1 \%$ Triton X-100, $0.1 \%$ sodium deoxycholate, and proteinase inhibitors). Chromatin was sheared by sonication using Bioruptor to an average fragment size of $500 \mathrm{bp}$, and then incubated with $2 \mu \mathrm{g}$ of the antibody (ATF3, sc-188; p53, sc-126; p300, sc-585) or normal IgG (rabbit, sc-3888; mouse, sc-2025) purchased from Santa Cruz, at $4{ }^{\circ} \mathrm{C}$ overnight. Immunocomplexes were precipitated with $30 \mu \mathrm{l}$ of ssDNAprotein A/G agarose (Millipore) at $4{ }^{\circ} \mathrm{C}$ for $2 \mathrm{~h}$, and sequentially washed with Buffer I $(50 \mathrm{mM}$ Tris- $\mathrm{HCl}$, pH8.0, $150 \mathrm{mM} \mathrm{NaCl}, 1$ \% SDS, $0.5 \%$ sodium deoxycholate, $1 \% \mathrm{NP} 40$, and $1 \mathrm{mM}$ EDTA), Buffer II (buffer I with $500 \mathrm{mM} \mathrm{NaCl}$ ), Buffer III $(50 \mathrm{mM}$ Tris- $\mathrm{HCl}$, pH8.0, $250 \mathrm{mM} \mathrm{LiCl}, 0.5 \%$ sodium deoxycholate, $1 \%$ NP 40, and $1 \mathrm{mM} \mathrm{EDTA}$ ), and TE buffer (50 mM Tris-
$\mathrm{HCl}$, pH8.0, and $1 \mathrm{mM}$ EDTA). Bound chromatin was eluted with $0.3 \mathrm{ml}$ of Elution buffer $(50 \mathrm{mM}$ Tris- $\mathrm{HCl}$, pH8.0, $1 \%$ SDS, and $1 \mathrm{mM}$ EDTA). After reversal of crosslinking, RNase A and Proteinase $\mathrm{K}$ was added, and DNA was purified by phenol extraction and ethanol precipitation. For re-ChIP assays, chromatin immunoprecipitated with the ATF3 antibody was eluted in $0.15 \mathrm{ml}$ of Elution buffer, and then diluted by 20 times with reChIP buffer (20 mM Tris-HCl, pH8.0, $150 \mathrm{mM} \mathrm{NaCl}$, $1 \%$ Triton X-100, and 2 mM EDTA), followed by incubation with the p53 antibody as described above.

\section{ChIP-seq and data analysis}

ChIP-seq libraries were prepared according to standard protocols using Biosicentific's DNA Sample Kit (cat\#514101) [50]. Libraries were sequenced using Illumina $\mathrm{Hi}$-Seq platforms. Sequence reads were aligned to the Human Reference Genome (assembly hg19) using Burrows-Wheeler Alignment (BWA) Tool Version 0.6.1. Peak identification, overlapping, subtraction and feature annotation of enriched regions were performed using Hypergeometric Optimization of Motif EnRichment suite (HOMER). Heatmaps and intensity plots of peaks were generated by Perl script, $\mathrm{R}$ and/or java Treeview. HOMER was used to check motif enrichment.

\section{Microarray data analysis}

Total RNA was prepared using Agilent Total RNA Isolation Mini Kit (cat\# 5185-6000). Microarray expression profiling was performed using HumanHT-12 v 4.0 Expression BeadChip (Illumina). Data were preprocessed and normalized by GenomeStudio. Differentially expressed genes were identified by Bioconductor limma package and GenePattern. Heatmap view of differentially expressed genes was created by Cluster and Java Treeview. GO term enrichment was determined using DAVID.

\section{Western blotting and quantitative PCR}

Western blotting assays were performed as described previously [16]. In brief, cells were lysed in RIPA buffer containing $50 \mathrm{mM}$ Tris- $\mathrm{HCl}, \mathrm{pH}$ 7.4, 1 \% Nonidet P-40, $0.25 \%$ sodium deoxycholate, $150 \mathrm{mM} \mathrm{NaCl}, 1 \mathrm{mM}$ EDTA, $1 \mathrm{mM}$ PMSF, and $1 \mathrm{mM} \mathrm{NaF}, 1 \mathrm{mM} \mathrm{Na} \mathrm{VO}_{4}$, and protease inhibitor cocktail (Roche), and then resolved in SDS-polyacrylamide electrophoresis for immunoblotting. Quantitative PCR assays were carried out using SYBR Green as described elsewhere [49].

\section{Availability of supporting data}

The data sets supporting the results of this article are available in the GEO with the accession number GSE74363 (http://www.ncbi.nlm.nih.gov/geo/query/acc.cgi?token=yfoz ycagbfojfkz\&acc=GSE74363). 


\section{Additional files}

Additional file 1: This pdf file contains Figure S1, S2 and S3. (PDF $531 \mathrm{~kb}$ )

Additional file 2: Table S1. A list of unique genes containing overlapped ATF3 and p53 peaks where both ATF3 and p53 motifs are present. (XLSX $32 \mathrm{~kb}$ )

\section{Competing interests}

The authors declare that they have no competing interests.

\section{Authors' contributions}

JZ analyzed most of the ChIP-seq and microarray data. XL validated the ChIP-seq and microarray results. MG prepared ChIP-seq and microarray samples. CY conceived the study, analyzed and organized the data with JY. CY wrote while JY edited the manuscript. All authors read and approved the final manuscript.

\section{Acknowledgements}

We thank Dr. Bert Vogelstein and Dr. Todd Waldman for providing cell lines and plasmids.

\section{Funding}

This work was supported by National Institutes of Health grants (R01CA139107, and R01CA164006), and a US Department of Defense award (W81XWH-15-1-0049) to CY.

\section{Author details}

${ }^{1}$ Department of Medicine, Division of Hematology and Oncology, Northwestern University Feinberg School of Medicine, Chicago, IL, USA ${ }^{2}$ Georgia Cancer Center, Augusta University, Augusta, GA, USA. ${ }^{3}$ Department of Biochemistry and Molecular Biology, Medical College of Georgia, Augusta University, Augusta, GA, USA. ${ }^{4}$ Center for Cell Biology and Cancer Research, Albany Medical College, Albany, NY, USA.

\section{Received: 8 December 2015 Accepted: 26 April 2016}

Published online: 04 May 2016

\section{References}

1. Pennacchio LA, Bickmore W, Dean A, Nobrega MA, Bejerano G. Enhancers: five essential questions. Nat Rev Genet. 2013;14:288-95

2. Levine M, Cattoglio C, Tjian R. Looping back to leap forward: Transcription enters a new era. Cell. 2014;157:13-25

3. Visel A, Blow MJ, Li Z, Zhang T, Akiyama JA, Holt A, Plajzer-Frick I, Shoukry M, Wright C, Chen F, Afzal V, Ren B, Rubin EM, Pennacchio LA. ChIP-seq accurately predicts tissue-specific activity of enhancers. Nature. 2009:457:854-8.

4. Creyghton MP, Cheng AW, Welstead GG, Kooistra T, Carey BW, Steine EJ, Hanna J, Lodato MA, Frampton GM, Sharp PA, Boyer LA, Young RA, Jaenisch R. Histone H3K27ac separates active form poised enhancers and predicts developmental state. Proc Natl Acad Sci USA. 2010;107:21931-6.

5. Rada-Iglesias A, Bajpai R, Swigut T, Brugmann SA, Flynn RA, Wysocka J. A unique chromatin signature uncovers early developmental enhancers in humans. Nature. 2011:470:279-83.

6. Zaret KS, Carroll JS. Pioneer transcription factors: Establishing competence for gene expression. Genes Dev. 2011;25:2227-41.

7. Weinhold N, Jacobsen A, Schultz N, Sander C, Lee W. Genome-wide analysis of noncoding regulatory mutations in cancer. Nat Genet. 2014;46:1160-5.

8. Wolford CC, McConoughey SJ, Jalgaonkar SP, Leon M, Merchant AS, Dominick JL, Yin X, Chang Y, Zmuda EJ, O'Toole SA, Millar EKA, Roller SL, Shapiro CL, Ostrowski MC, Sutherland RL, Hai T. Transcription factor ATF3 links host adaptive response to breast cancer metastasis. J Clin Invest. 2013; 123:2893-906.

9. Wu X, Nguyen B, Dziunycz P, Chang S, Brooks Y, Lefort K, Hofbauer G, Dotto G. Opposing roles for calcineurin and ATF3 in squamous skin cancer. Nature. 2010;465:368-72

10. Yuan X, Yu L, Li J, Xie G, Rong T, Zhang L, Chen J, Meng Q, Irving AT, Wang D, Williams ED, Liu JP, Sadler AJ, Williams BR, Shen L, Xu D. ATF3 suppresses metastasis of bladder cancer by regulating gelsolin-mediated remodeling of the actin cytoskeleton. Cancer Res. 2013;73:3625-37.
11. Wang Z, Xu D, Ding H-F, Kim J, Zhang J, Hai T, Yan C. Loss of ATF3 promotes Akt activation and prostate cancer development in a Pten knockout mouse model. Oncogene. 2015;34:4975-84.

12. Gold ES, Ramsey SA, Sartain MJ, Selinummi J, Podolsky I, Rodriguez DJ, Moritz RL, Aderem A. ATF3 protects against atherosclerosis by suppressing 25hydroxycholesterol-induced lipid body formation. J Exp Med. 2012;209:807-17.

13. Hoetzenecker W, Echtenacher B, Guenova E, Hoetzenecker K, Woelbing F, Bruck J, Teske A, Valtcheva N, Fuchs K, Kneilling M, Park J-H, Kim K-H, Kim K-W, Hoffmann P, Krenn C, Hai T, Ghoreschi K, Biedermann T, Rocken M. ROSinduced ATF3 causes susceptibility to secondary infections during sepsisassociated immunosuppression. Nat Med. 2012;18:128-34.

14. Zhou H, Shen D-F, Bian Z-Y, Zong J, Deng W, Zhang Y, Guo Y-Y, Li H, Tang Q-Z. Activating transcription factor 3 deficiency promotes cardiac hypertrophy, dysfunction, and fibrosis induced by pressure overload. PLoS One. 2011:6:e26744

15. Beleza-Meireles A, Tohonen V, Soderhall C, Schwentner C, Radmayr C, Kockum I, Nordenskjold A. Activating transcription 3: A hormone responsive gene in the etiology of hypospadias. Eur J Endocrinol. 2008;158:729-39.

16. Yan C, Lu D, Hai T, Boyd DD. Activating transcription factor 3, a stress sensor, activates p53 by blocking its ubiquitination. EMBO J. 2005;24:2425-35.

17. Gilchrist M, Thorsson V, Li B, Rust AG, Korb M, Roach JC, Kennedy K, Hai T, Bolouri $H$, Aderem A. Systems biology approaches identify ATF3 as a negative regulator of Toll-like receptor 4. Nature. 2006:441:173-8.

18. Yan C, Boyd DD. ATF3 regulates the stability of p53: A link to cancer. Cell Cycle. 2006;5:926-9.

19. Hai T, Wolfgang CD, Marsee DK, Allen AE, Sivaprasad U. ATF3 and stress responses. Gene Expression. 1999;7:321-5.

20. Walter $P$, Ron D. The unfolded protein response: From stress pathway to homeostatic regulation. Science. 2011;334:1081-6.

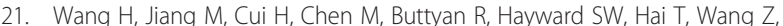
Yan $C$. The stress response mediator ATF3 represses androgen signaling by binding the androgen receptor. Mol Cell Biol. 2012;32:3190-202.

22. Cui H, Guo M, Xu D, Ding Z-C, Zhou G, Ding H-F, Zhang J, Tang Y, Yan C. The stress-responsive gene ATF3 regulates the histone acetyltransferase Tip60. Nat Commun. 2015;6:6752.

23. Kim J-S, Bonifant C, BunZ F, Lane WS, Waldman T. Epitope tagging of endogenous genes in diverse human cell lines. Nucleic Acid Res. 2008;36:e127.

24. Wolfgang $C D$, Liang G, Okamoto $Y$, Allen AE, Hai T. Transcriptional autorepression of the stress-inducible gene ATF3. J Biol Chem. 2000;275:16865-70.

25. Newman JRS, Keating AE. Comprehensive identification of human bZIP interactions with coiled-coil arrays. Science. 2003;300:2097-101.

26. Kiryu-Seo S, Kato R, Ogawa T, Nakagomi S, Nagata K, Kiyama H. Neuronal injuryinducible gene is synergistically regulated by ATF3, c-Jun, and STAT3 through the interaction with Sp1 in damaged neurons. J Biol Chem. 2008;283:6988-96.

27. Hu D, Gao X, Morgan MA, Herz H-M, Smith ER, Shilatifard A. The MLL3/MLL4 branches of the COMPASS family function as major histone H3K4 monmethylases at enhancers. Mol Cell Biol. 2013:33:4745-54

28. Frietze S, Wang R, Yao L, Tak YG, Ye Z, Gaddis M, Witt H, Farnham PJ, Jin VX. Cell type-specific binding patterns reveal that TCF7L2 can be tethered to the genome by association with GATA3. Genome Biol. 2012;13:R52.

29. Pan Y, Chen H, Siu F, Kilberg MS. Amino acid deprivation and endoplasmic reticulum stress induce expression of multiple activating transcription factor-3 mRNA species that, when overexpressed in HepG2 cells, modulate transcription by the human asparagine synthetase promoter. J Biol Chem. 2003:278:38402-12.

30. Bottone FG, Moon Y, Kim JS, Alston-Mills B, Ishibashi M, Eling TE. The antiinvasive activity of cyclooxygenase inhibitors is regulated by the transcription factor ATF3 (activating transcription factor 3). Mol Cancer Ther. 2005:4:693-703.

31. Hackl C, Lang SA, Moser C, Mori A, Fichtner-Feigl S, Hellerbrand C, Dietmeier W, Schlitt HJ, Geissler EK, Stoeltzing O. Activating transcription factor-3 (ATF3) functions as a tumor suppressor in colon cancer and is up-regulated upon heatshock protein 90 (Hsp90) inhibition. BMC Cancer. 2010;10:668.

32. Mo P, Wang H, Lu H, Boyd DD, Yan C. MDM2 mediates ubiquitination and degradation of activating transcription factor 3. J Biol Chem. 2010;285:26908-15.

33. Calo E, Wysocka J. Modifiation of enhancer chromatin: What, how, and why? Mol Cell. 2013:49:825-37.

34. Vousden $\mathrm{KH}$, Prives $\mathrm{C}$. Blinded by the light: The growing complexicty of p53. Cell. 2009:137:413-31.

35. Botcheva K, McCorkle SR, McCombie WR, Dunn JJ, Anderson CW. Distinct p53 genomic binding patterns in normal and cancer-derived cancer cells. Cell Cycle. 2011;10:4237-49. 
36. Menendez D, Nguyen T-A, Freudenberg JM, Mathew VJ, Anderson CW, Jothi R, Resnick MA. Diverse stresses dramatically alter genome-wide p53 binding and transactivation landscape in human cancer cells. Nucleic Acid Res. 2013;41:7286-301.

37. Broz DK, Mello SS, Bieging KT, Jian D, Dusek RL, Brady CA, Sidow A, Attardi LD. Global genomic profiling reveals an extensive p53-regulated autophagy program contributing to key p53 responses. Genes Dev. 2013;27:1016-31.

38. Fan F, Jin S, Amundson SA, Tong T, Fan W, Zhao H, Zhu X, Mazzacuratin L, Li X, Petrik KL, Fornace AJ, Rajasekaran B, Zhan Q. ATF3 induction following DNA damage is regulated by distinct signaling pathways and overexpression of ATF3 protein suppresses cells growth. Oncogene. 2002;21: 7488-96.

39. Garber M, Yosef N, Goren A, Raychowdhury R, Thielke A, Guttman M, Robinson J, Minie B, Chevrier N, Itzhaki Z, Blecher-Gonen R, Bornstein C, AmannZalcenstein D, Weiner A, Friedrich D, Meldrim J, Ram O, Cheng C, Gnirke A, Fisher S, Friedman N, Wong B, Bernstein BE, Nusbaum C, Hacohen N, Regev A, Amit I. A high-throughput chromatin immunoprecipitation approach reveals principles of dynamic gene regulation in mammals. Mol Cell. 2012;47:810-22.

40. Chen B, Wolfgang C, Hai T. Analysis of ATF3, a transcription factor induced by physiological stresses and modulated by gadd153/Chop10. Mol Cell Biol. 1996;16:1157-68.

41. Wei S, Wang H, Lu C, Malmut S, Zhang J, Ren S, Yu G, Wang W, Tang DD, Yan C. The activating transcription factor 3 protein suppresses the oncogenic function of mutant p53 proteins. J Biol Chem. 2014;289:8947-59.

42. Kouwenhoven EN, Oti M, Niehues H, van Heeringen SJ, Schalkwijk J, Stunnenberg HG, van Bokhoven H, Zhou H. Transcription factor p63 bookmarks and regulates dynamic enhancers during epidermal differentiation. EMBO Rep. 2015;16:863-78.

43. Ikura T, Tashiro S, Kakino A, Shima H, Jacob N, Amunugama R, Yoder K, Izumi S, Kuraoka I, Tanaka K, Kimura H, Ikura M, Nishijubbo S, Ito T, Muto A, Miyagawa K, Takeda S, Fishel R, Igarashi K, Kamiya K. DNA damagedependent acetylation and ubiquitiantion of H2AX enhances chromatin dynamics. Mol Cell Biol. 2011;27:70287040.

44. Lukas J, Lukas C, Bartek J. More than just a focus: The chromatin response to DNA damage and its role in genome integrity maintenance. Nat Cell Biol. 2011;13:1161-9.

45. Ayrapetov MK, Gursoy-Yuzugullu O, Xu C, Xu Y, Price BD. DNA double-strand breaks promote methylation of histone $\mathrm{H} 3$ on lysine 9 and transient formation of repressive chromatin. Proc Natl Acad Sci USA. 2014;111:9169-74.

46. Tanaka Y, Nakumura A, Morioka MS, Inoue S, Tamamori-Adachi M, Yamada K, Taketani K, Kawauchi J, Tanaka-Okamoto M, Miyoshi J, Tanaka H, Kitajima S. System analysis of ATF3 in stress response and cancer reveals opposing effects on pro-apoptotic genes in p53 pathway. PLoS One. 2011;6:e26848.

47. Yonger ST, Kenzelmann-Broz D, Jung H, Attardi LD, Rinn JL. Integrative genomic analysis reveals widespread enhancer regulation by p53 in response to DNA damage. Nucleic Acid Res. 2015:43:4447-62.

48. Lang L, Ding H-F, Chen X, Sun S-Y, Liu G, Yan C. Internal ribosome entry site-based bicistronic in situ reporter assays for discovery of transcriptiontargeted lead compound. Chem Biol. 2015;22:957-64.

49. Yan $\mathrm{C}$, Boyd DD. Histone $\mathrm{H} 3$ acetylation and $\mathrm{H} 3 \mathrm{~K} 4$ methylation define distinct chromatin regions permissive for transgene expression. Mol Cell Biol. 2006;26:6357-71.

50. Yu J, Yu J, Mani R, Cao Q, Brenner CJ, Cao X, Wang X, Wu L, Li J, Hu M, Gong Y, Cheng H, Laxman B, Vellaichamy A, Shankar S, Li Y, Dhanasekaran SM, Morey R, Barrette T, Lonigro RJ, Tomlins SA, Varambally S, Qin ZS, Chinnaiyan AM. An integrated network of androgen receptor, polycomb, and TMPRSS2-ERG gene fusions in prostate cancer progression. Cancer Cell. 2010;17:443-54.

\section{Submit your next manuscript to BioMed Central and we will help you at every step:}

- We accept pre-submission inquiries

- Our selector tool helps you to find the most relevant journal

- We provide round the clock customer support

- Convenient online submission

- Thorough peer review

- Inclusion in PubMed and all major indexing services

- Maximum visibility for your research

Submit your manuscript at www.biomedcentral.com/submit
Biomed Central 